\title{
DIGIT SPEECH RECEPTION THRESHOLD TESTING IN TSWANA/ENGLISH SPEAKERS
}

\author{
Katijah Khoza, Lebogang Ramma*, Munyane Mophosho and Duduetsang Moroka \\ *University of Cape Town \& University of the Witwatersrand, South Africa
}

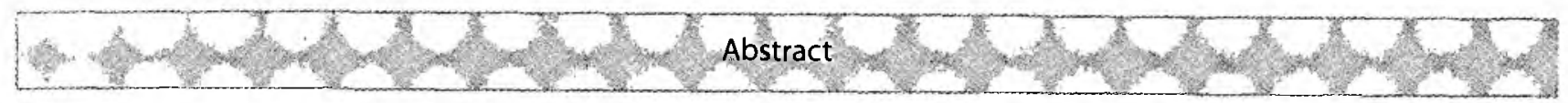

The purposeofthisstudy wastoestablish whether digit stimuliofferamoreaccuratemeasurefor Speech ReceptionThreshold (SRT) testing when assessing first-languageTswana (or Setswana), second-language English speakers, as compared to an English wordlist (CID W-1) and a Tswana wordlist. Forty Tswana first language speaking participants (17 males and 23 females) agedbetween 18 and 25 years, participated in this study. All participantswereundergraduatestudentsatatertiary institution in Johannesburg, Gauteng. This study utilized a quantitative singlegroup correlation design which allowedfora comparison between three SRT scores (CID-SRT,T-SRT, andD-SRT). Participants underwent basic audiological assessment procedures comprising of otoscopy, tympanometry, conventional pure tone audiometry and SRT testing. SRT measures were established using monitored live voice testing. Basic audiometric data were descriptively analyzed to ensure that hearing function was within normal limits, and PTA-SRT averages and means were calculated. Furthermore, analysis of the SRT-PTAcorrelationdatawasconducted throughtheuseofthenonparametricSpearman'scorrelationcoefficientandlinear regression. Results from this study were statistically significant $(p<.05)$ and indicated that digit-pairs were not the most effective stimuli for establishing SRT, compared to the CIDW-1 and Tswana wordlists. On the contrary, findings of the current study revealed that PTA-SRT comparison was best in Tswana $(r=0.62)$, followed very closely by CIDW-1 $(r=0.61)$, and lastly digit- pairs $(r=0.60)$. The results however, confirm the efficacy of using digit pairs as alternative stimuli when more appropriate speech stimuli for the establishment of SRT are unavailable, as the correlation between SRT for digit pairs and PTA was also a strong one $(r=0.60)$. Linear regression analyses indicated that all three lists were acceptable speech stimuli forthepopulationunderinvestigation withthestandarderrorofestimatebeingsignificantlysmallerthanthe $5 \mathrm{~dB}$-stepused to collect the data (1.62 for Tswana, 3.56 for CID W-1, and 3.80 for digit-pairs).

Key words: digit pairs, speech reception, language, word lists, audiology.

A major challenge facing practitioners in the field of speech-language pathology is the appropriate assessment of communication differences and disorders in multilingual/multicultural populations (Battle, 1998; Cole, 1989). The same is true for audiology, particularly in a country like South Africa where 11 official languages are spoken, with South African Sign language also progressing to the same status as the other languages. In addressing this challenge, audiologists are required to utilize speech assessment tools that are often unstandardized. Therefore, such assessment practices may result in unreliable and inaccurate diagnosis of hearing impairment in approximately $80 \%$ of the country's population (Ramkissoon \& Khan, 2003). One of the solutions employed by audiologists working with non-native English speakers, a practice that has been strongly criticized, is the modification of standardized word lists which use fewer words deemed most familiar to that population (Meyer \& Bilger, 1997). Reduction of wordset size on a word list for convenience is an inappropriate solution to this problem.

Managing linguistic diversity in audiological assessment practice is made more formidable when one considers the mismatch between clients who speak a Black African firstlanguage (BAFL), and audiologists, the majority of whom do not speak an indigenous African language. The Health Professions Council of South Africa (HPCSA, 2008) reports that of the 147 audiologists registered in 2008, 23 are Black; and of the 1374 speech and hearing therapists regis- tered, 56 are Black. It must be noted that Black, in this case, includes Indian and Coloured audiologists, who are more than likely non-BAFL speakers. No category termed "African-language speaker" exists within the HPCSA register so accurate figures of such professionals are unavailable. The negligible number of qualified indigenous, Black African first-language speakers in the profession of speech-language pathology and audiology in South Africa does not seem to have increased from the less than $1 \%$ reported five years ago by Ramkissoon and Khan (2003).

Arguably, audiologists who do not recognize nor acknowledge that linguistic differences affect hearing assessment and management (Ramkissoon \& Khan, 2003) may be violating a basic human right. Indeed, audiologists may be described as acting against the South African government's regulations of making all 11 official languages equal in terms of use and status recognition (Republic of South Africa, 1996). The language rights of all South African citizens are firmly entrenched in, inter alia, sections 6, 29, 30 and 31 of the Constitution of the Republic of South Africa, Act 108 of 1996. In addition to providing for the status of the 11 official languages, the Constitution also prescribes affirmative action for the African languages. Given

Author Contact: Post Office Box 57

Wits, 2050, South Africa

E-mail:Katijah.Khoza@wits.ac.za 
this change in government policies and the real emphasis on respecting individual rights, a higher impetus needs to be placed on developing and using speech assessment tools in audiological practice.

Appropriate audiological assessment materials are needed not just to address the issue of linguistic rights, but also to ensure test reliability and validity. A lack of familiarity with speech assessment materials may adversely affect speech audiometric results of clients who lack the required level of familiarity with the language to be able to achieve accurate scores. Clients who are less familiar with the language in which the test stimuli are presented may not perform as well as native speakers of that language, even if their actual hearing abilities and true SRT scores may be equal to or even better than those of first language speakers. Hence, audiologists need to take cognizance of the clients' native languages in order to obtain accurate test results that best describe the client's hearing status. This can be achieved if more emphasis is placed on development of wordlists in all languages, hence the current study on second language English speakers who speak Tswana as their first language. Given the lack of adequate test materials in South Africa's indigenous African languages, digit-pair stimuli may be appropriate for use when testing the hearing of a South African citizen who does not speak English or Afrikaans as their first language.

Carhart (1951) defined speech audiometry as a versatile clinical tool wherein standardized samples of language are presented through a calibrated system to measure an individual's ability to hear speech stimuli. As early as 1976 , the value of speech audiometry was recognized in the literature as not only a measure of peripheral hearing, but also as the total study of an individual's comprehension of the language, knowledge of the language, audition, and concentration, particularly in the absence of visual cues in the form of lip reading (Lyregaard, 1976). This claim highlights the need for ensuring that selection of appropriate test materials, as well as the way in which speech testing is conducted in order to enhance reliability and validitity of speech audiometry.

Speech audiometry is divided into two main areas, namely suprathreshold speech discrimination (SD) (or "word recognition') and Speech Reception Threshold (SRT) testing. SD testing assesses an individual's ability to understand speech as a function of his or her ability to differentiate between sounds (Hodgson, 1980). SRT testing, which is the focus of this paper, provides an index of hearing sensitivity for speech and serves as a baseline measure for determining the presentation levels for suprathreshold word recognition tests (Bess \& Humes, 2003). Most importantly, SRT provides the audiologist with scores that serve as a reliability check of an individual's pure tone average (PTA). Therefore results from SRT testing allow for the cross-check principle to be implemented (Jerger \& Heyes, 1976), where SRT scores are correlated with the PTA to confirm the results of the audiogram, hence confirming the reliability and validity of the hearing test results. Where the audiologist does not speak the clients' language, discrepancies in results can occur due to various reasons, one of which is failure to understand instructions for testing, if an interpreter is not utilized. Discrepancies in PTA-SRT correlation can also be indicative of a non-organic hearing loss (Jerger \& Jerger, 1981), hence failure to accurately obtain SRT scores could influence accuracy in making this diagnosis. Such problems could be avoided or minimized if alternative stimuli were available to assess those individuals who do not speak the language of the commonly used English standardized tests.

Speech audiometry results are also significant in the process of selecting hearing amplification. So not only may word lists in current use negatively influence the process of diagnosis but also that of habilitation/rehabilitation. Arguably, this may result in a disservice to a large portion of the South African population. This view concurs with Lewis and Penn (1989) who declared that the use of tests standardized on foreign populations may cause great problems when implemented with second language English speakers. This is because such tests may contain linguistically and culturally biased items that may potentially lead to several problems amongst which are misinterpretation of test results, inaccurate testing (due to lack of interpreters), and misdiagnosis. It is not surprising, therefore, that testing multilingual and multicultural populations would be cumbersome if heavy reliance is placed on the diagnostic tools such as the SRT word lists in current use.

The history of speech testing clearly displays a progressively developing field of audiology internationally. However, locally a significant amount of work still needs to be conducted in developing this area to ensure that an efficacious service is provided to all individuals requiring audiological services in the country. As far back as 1804 researchers such as Pfingstein were reported to have been among the first people to assess an individual's ability to hear speech sounds as well as classify the degree of hearing loss (Feldman, 1970). Hudgins, Hawkins, Karlin, and Stevens (1947) report that in 1926, the American Federation of Organizations of the Hard of Hearing first reported on the widely used test that was developed to measure Speech Reception Threshold (SRT), viz. the Western Electric 4A. This test consisted of digit pairs produced as spondees. This was subsequently modified to the Western Electric $4 \mathrm{C}$ which was utilized until Hudgins et al (1947) specified four main criteria needed for selecting stimulus material for SRT testing (Berger, 1977). These criteria are considered to be crucial for every speech test (Knight, 1997).

Speech reception threshold tests, such as the Central Institute for the Deaf (CID) W-1 were developed using Hudgins et al criteria, and are widely used in audiological practice to date. The criteria to be considered when selecting stimuli material for SRT testing are :

- familiarity,

- phonetic dissimilarity,

- representative sample of English speech sounds, and

- homogeneity and audibility of the test materials (Hudgins et al., 1947).

At least two of these criteria are of significant concern when it comes to speech testing of the target group for this study i.e the South African citizen who does not speak English as their first language. The use of English speech stimuli with clients who speak another language clearly violates the criterion of familiarity. 
For the population under current investigation, it is clear that the tests in current use do not meet the first and third criteria since English is not their first language and so the level of familiarity with the stimuli material may be significantly decreased. Furthermore, the sample of speech sounds is representative of English speech sounds and not that of the language of the individuals being evaluated. These problems may be further compounded by the fact that these commonly used tests are American standardized on American populations, and so may have decreased validity even with the South African English first language speaker. Words such as "horseshoe, drawbridge, whitewash" are reported to be particular to American English and often do not seem to be familiar to individuals who do not speak standard American English (Ramkissoon et al., 2002), and this may also include the general South African English first language speakers.

In an African context, it should come as no surprise that the traditional Western spondaic word lists used in speech audiometry, standardized in countries such as the United States of America, may be difficult and unfamiliar to the second language English speaker. Ramkissoon et al. (2002) emphasized the important fact that it is crucial for all avenues to be explored in order to develop the most accurate and efficient clinical test battery for SRT testing for first language as well as second language English speakers.

Hence Ramkissoon et al (2002) explored the use of digit pairs as alternative stimuli for SRT testing. These authors used digit pairs on 12 non-native and 12 native English speakers and found that digit pairs effectively measured SRT for both groups, particularly so for the non-native English speaking group. Although the sample size in this study was deemed small, with a wide range of languages being spoken by the participants, the fact that the participants had minimum spoken English, with less than a year's exposure to the language, made the results of the study important to speech audiometry testing in multilingual populations. Availability of effective, valid and reliable stimuli for SRT testing is critical since careful selection of test materials plays a crucial role in improving the validity of diagnostic audiology and in enhancing audiologic habilitation.

The search for more appropriate speech stimuli in African languages is further compounded by the paucity of research on African languages in South Africa, and this has led to audiologists in this country becoming dependent on English-based principles to guide their selection of test materials (Ramkissoon \& Khan, 2003). Tswana, for example, is classified under the same linguistic category as some of South Africa's native languages such as SeSotho and SePedi in terms of their syntactic structure, which is vastly different from English (Pillay, 1996). Therefore it is critical to bear in mind while performing speech audiometry that English and Tswana differ markedly in terms of morphology and grammatical structure (Donaldson, 1991). Therefore, utilizing the CID W-1 on Tswana speaking individuals may be inappropriate and may yield unreliable results by introducing cultural and linguistic bias to the validity and reliability of testing. These formal tests may result in depressed speech audiometry scores that have no relation to the auditory acuity of second language English speakers, hence confounding diagnostic findings.
Variables such as linguistic background, dialectal differences, vocabulary and accent differences between speakers make it difficult to create standardized, language-specific test stimuli that are appropriate for use on non-native English speakers (Jacobson \& Trail, 1986). So, although informal non-standardized language specific wordlists are available in Tswana and other African languages, they may be administered by audiologists who are first language English or Afrikaans speakers utilizing monitored live voice testing (Ramkissoon \& Khan, 2003). These audiologists may have difficulty pronouncing the words on these wordlist due to the fact that many African languages are multisyllabic tonal languages, i.e. each syllable in a word has its particular value and a second language speaker of the language may not always be aware of this. This lack of awareness may consequently lead to erroneous production of test stimuli. This situation may necessitate reduction of test stimuli or set sizes for convenience, which has been shown to falsely improve SRT scores, thereby creating an impression that the person's scores are better than they actually are (Punch \& Howard, 1985). This compounds the problem even further since these wordlists have not been formally devised and standardized following recommended guidelines such as the four criteria recommended by Hudgins, Hawkins, Karlin, and Stevens in 1947.

The current study was therefore aimed at investigating the effectiveness of three wordlists in establishing SRT for second language English speakers who speak Tswana as their first language. The wordlists comprised three different types of stimuli, namely digit pairs (randomly paired English numbers from 1-10, excluding the only bisyllabic digit, 7); the CID W-1 wordlist, and a Tswana wordlist. Specifically, this was done with the aim of determining whether digit SRT testing would yield more accurate and more reliable results. Digit pairs have been reported as not only more familiar, but also more intelligible in comparison to other speech material (Ramkissoon et al, 2002), they are reported to be non-linguistically loaded, used in daily living, and may therefore be more familiar to the target population (Hudgins et al., 1947; Miller, Heise, \& Lichten, 1951). In their study, Ramkissoon et al. (2002) found that digit pairs were effective in establishing SRT in clients with limited English proficiency (with an Asian or European first language). However there is little other evidence in the literature regarding the effectiveness of digit stimuli in establishing the SRT in second language English speakers particularly those who are first language African language speakers, hence the need for this study.

\section{Methodology}

Aim of the study:

The main objective of the study was to establish whether digit stimuli offer a more accurate measure for Speech Reception Threshold (SRT) testing when assessing second language English speakers who speak Tswana as their first language.

Specific aim of the study:

To determine if digit stimuli are more accurate than the CID W-1 wordlist and the Tswana wordlist in measuring the SRT scores among second language English speakers who speak Tswana as their first language. 
The following were the hypotheses for the current study: $\mathrm{H}_{0}$ : The participants' SRT-PTA correlation would be the same for all 3 lists used.

$\mathrm{H}_{1}$ : The participants'SRT-PTA correlation would be different (i.e. participants would present with different SRTPTA correlations).

Research design:

This study design is quantitative; with the utilization of the single group correlation design (Rosenthal \& Rosnow, 1991). The sample group comprised of first language Tswana speakers with English as a second language. The digit-SRT scores, CID W-1-SRT scores, informal Tswana wordlistSRT scores, and pure tone average scores for each participant were obtained and SRT-PTA correlations were established to determine which tests yielded the best scores.

Sample:

Non-random convenience sampling of 40 participants (17 males and 23 females) was used. The participants were all from Botswana, and spoke Tswana as their first language. Participants were aged between 18 and 25 years (mean of 22 years) and acquired English as their second language after the age of three years. All participants were undergraduate students at a university in Johannesburg. It is acknowledged that the level of education of the participants in the current study limits the generalizability of results to the general South African population, including those with no or little formal education.

\section{Selection criteria}

1. All participants had to have normal hearing bilaterally to be included in the study to eliminate the impact of peripheral hearing impairment on speech audiometry results. Audiometric results were obtained for hearing for each ear thus the results for 80 "ears" were used $(\mathrm{N}=80)$.

2. The participants were required to be first language Tswana speakers with English as the second language. McLaughlin (1984)'defines English second language acquisition as that which occurs after the age of 3 , distinguishing it from simultaneous bilingual acquisition, and this was the definition adopted for this study. Therefore participants were required to have acquired English after the age of three.

3. The participants had to be between 18 and 28 years of age. This was to control for effects that presbycusis could have on the participants' performance (Katz, 2002), as well as to avoid age-effects related to one's speech and language abilities (Chapey, 1994).

Participants were recruited through the Botswana students' association at the university as well as by randomly approaching other Tswana speaking individuals within the university community. Permission to conduct the study was obtained from the Human Research Ethics Committee (Protocol Number: H050402) and approval to conduct the study was obtained from all relevant authorities and departments prior to the conduction of the study.

Ethical considerations in this study were guided by the Principles of the South African Medical Research Council (South African Medical Research Council, 2003). Informed consent was obtained prior to individuals being included in the study.

\section{Data Collection}

All data was collected utilizing equipment from the University Speech and Hearing clinic. The tester who conducted all testing was proficient in both English and Tswana.

\section{Materials and Procedures}

The following instruments and procedures were included in the research protocol:

1. Case history interview: semi-structured interviews were conducted in order to obtain demographic data from participants. The interviews aided in collecting information about the participants' hearing status as well as their proficiency in both languages (English and Tswana). The participants were required to use a scale to rate their proficiency in both languages, at the time of the study, as 'good', 'average' or 'poor'. The distinction between 'average' and 'good' was based on participants' exposure to English and their use of the language both as a medium of instruction and mode of communication on a daily basis before being enrolled at an English-medium university.

2. An otoscopic examination was conducted using a Mini Heine otoscope. This was performed in order to ensure that the eardrum was visible and intact, with the observation of the normal light reflex; as well as to determine if any evidence of ear canal collapse was present (Martin \& Clark, 2003). In addition, the examination was conducted in order to ensure that the ear canal was free of cerumen or other obstruction, as impacted cerumen has been reported to cause audible tinnitus (Heller \& Bergman, 1953) which can have an impact on speech testing.

3. Impedance audiometry in the form of tympanometry was utilized to assess the status and integrity of middle ear functioning, using the GSI 33 tympanometer. Standard single frequency tympanometry using an $85 \mathrm{~dB}$ SPL tone set at $226 \mathrm{~Hz}$ was conducted. The primary purpose of impedance audiometry is to determine the status of the tympanic membrane and middle ear (Martin \& Clark, 2003) by obtaining a tympanogram for each ear. The tympanogram results were analyzed according to Jerger's classification system. Tympanograms are classified into types ie. types $A,-$ $A_{s}, A_{d} ; B ; C$ and $D$; with the type $A$ regarded as normal and all other types as abnormal (Katz, 2002). Participants presenting with the other types of tympanograms besides a type A were excluded from the study.

4. An Auricle audiometer was use to conduct conventional pure tone audiometry, with pulsed stimuli (for frequencies from $250 \mathrm{~Hz}$ to $8000 \mathrm{~Hz}$ ). Hearing thresholds were obtained via both air (using standard TDH-39 circumaural headphones) and bone conduction transducers, using the model B71 bone conductor. The bracketing technique was used with a starting level of $30 \mathrm{dBHL}$ since all participants presented with no apparent hearing loss. The criteria used to define normal hearing, was that of pure tone average (three frequency average of pure tone air-conduction thresholds at $500 \mathrm{~Hz}, 1000 \mathrm{~Hz}$, and $2000 \mathrm{~Hz}$ ) of $15 \mathrm{dBHL}$, with the absence of an air-bone gap (Jerger \& Jerger, 1981).

5. For SRT testing, three lists were used with each participant. It should be noted that participants were not all given the same list, but rather within each list, words were presented in a randomized order based on the participant's performance on the familiarization task. The first stimu- 
li wordlist was the traditional CID W-1 English wordlist (CID-SRT) which is traditionally used internationally as well as in most audiologic settings in South Africa (Appen$\operatorname{dix} \mathrm{A}$ ). The second wordlist was an informal Tswana trisyllabic wordlist (T-SRT) which has not been standardized but is used in some hospital institutions as well as schools for the hearing impaired in Johannesburg (Appendix B). The syllable structure of the words in this list is typical of the general Tswana syllables, as described by le Roux (1991), in that it ends in a vowel with the unstressed vowel being left out where syllabic consonants occur. This list was informally pre-tested on eight Tswana speaking support staff at the research site for familiarity with regard to their relative usage frequency, representative nature of the Tswana speech sounds, and audibility of the words used. It is acknowledged that although the list seems to also contain phonetic dissimilarity, this aspect was not formally assessed in the current study. Furthermore, although not formally researched, the trisyllabic nature of the Tswana wordlist appeared similar to the CID W-1 spondees with regards to the steepness of the psychometric function slope. The third stimuli list (D-SRT, Appendix C) was that of paired digits from 1 to 10 (excluding the bisyllabic digit 7). It should be noted that although the set size for the wordlists is 15 for the Tswana stimuli and digit pairs, and 36 for the CID-W1, this difference was not felt to have had an impact on the testing since the testing procedures followed were standardized from participant to participant. All testing was performed through monitored live voice. Although this mode of presentation is not highly recommended (Health Professions Council of South Africa, 2002) due to its recognized flaws such as the fact that physical attributes of speech vary significantly from person to person (Hood \& Pool, 1980), it has been observed to be the most widely used mode in South Africa (Ramkissoon \& Khan, 2003) and Botswana, and has also been reported to allow for greater flexibility and reduced testing time without compromising test-retest reliability (Frank \& Craig, 1984). The typical clinical procedure for SRT testing outlined by Katz (1994) was employed. Participants were familiarized with the test material at 40dBSL (40dB above PTA) before the evaluation commenced (Katz, 1994). The descending 5 $\mathrm{dB}$ step approach was utilized. The carrier phrase "say/Iri..." preceded the word-stimulus, which was presented with equal stress placed on each syllable. The peak volume unit meter (VU-meter) was consistently monitored to ensure that the presentation of each syllable peaked at 0 . The SRT score was taken as the level at which the participants obtained a score of 2 correct words out of 4 words ( $50 \%$ criterion). The SRT results, established for each of the three wordlists, were then correlated with PTA for each participant. The SRT-PTA correlation for each stimuli list was determined and comparisons made to determine which stimuli list yielded the bést PTA-SRT correlation.

Data Analysis

All basic audiometric data were analyzed to ensure that hearing function was within normal limits for all participants. Mean PTA-SRT differences were calculated. Furthermore, analysis of the SRT-PTA results was conducted through the use of the nonparametric Spearman's correlation coefficient and linear regression. This allowed compari- sons to be made among the three SRT scores (CID-SRT, TSRT, and D-SRT) in order to determine which one of the three SRT measures yielded scores that correlated best with the PTA results, while establishing whether the lists were acceptable speech stimuli for the population under investigation. The Spearman's correlation coefficient was thought to be suitable for this study because it is a better indicator of a relationship that may exist between two variables when the relationship is non-linear, such as in the current study. The value of the Spearman's correlation coefficient $(r)$ can vary from minus one $(-1)$ to plus one $(+1)$ with a zero $(0)$ indicating that the two variables do not vary together at all, while one (1) implies a perfect correlation. Furthermore, an $r$ value between 0 and 1 indicates that the two variables tend to increase or decrease together, while that between 0 and 1 implies that one variable increases as the other decreases. Lastly, -1 indicates a perfect negative or inverse correlation. The closer the correlation coefficient is to 1 , the stronger the correlation is between the variables being studied (Howell, 1999).

To statistically test the hypothesis, a significance level or a threshold p value (alpha - two tailed) of 0.05 was selected, which meant that there would be a $95 \%$ confidence level that results were not due to chance (Devlin, 2006).

Reliability and Validity

The following measures were adopted to improve the reliability and validity of results from this study:

Test Environment

A sound proof booth was used for the audiometric evaluation of participants so that measurements of auditory thresholds were not affected by background noise. This test environment was also kept constant across all participants. According to Schiavetti \& Metz (2002), the test environment must be appropriate to the task, and be kept constant across participants in order to prevent contamination of measurements.

Instrument Calibration

Annually scheduled calibration of the equipment (2 months before current data collection) had been performed and biologic calibration (on the day of each testing session) of the instrument was also regularly performed during the course of the study.

\section{Instruction to Participants}

Instructions to participants were clear and consistent across participants. For SRT testing, after the familiarization procedures, all participants were instructed to accurately repeat the words that the audiologist produced and were encouraged to guess when they were not sure what the word was as the intensity level decreased. These instructions were presented in English and Tswana depending on which list was being employed.

\section{Live voice testing}

The VU meter was constantly monitored during, SRT testing, and a second observer was present during the evaluation of 20 of the 40 participants to ensure tester reliability. The second observer was a final year Speech Therapy and Audiology student who was proficient.in both English and Tswana. 


\section{Results and Discussion}

From the case history interviews, no participant reported hearing difficulties or any family history of hearing impairment. No other significant case history factors that are known to have an impact on hearing or are associated with hearing impairment were reported. In terms of the participants' proficiency in each language, a majority (27) of participants indicated good proficiency in English and Tswana while the rest indicated average proficiency (Table 1 ).

Table 1. Participants'profile $(N=40)$

\begin{tabular}{|l|l|l|l|}
\hline Age & Gender & $\begin{array}{l}\text { English level of } \\
\text { Proficiency }\end{array}$ & $\begin{array}{l}\text { Tswana level of } \\
\text { Proficiency }\end{array}$ \\
\hline $\begin{array}{l}\text { Range: 18-25yrs } \\
\text { Mean :22yrs }\end{array}$ & $\begin{array}{l}\text { Female }=23 \\
\text { Male }=17\end{array}$ & $\begin{array}{l}\text { Average }=13 \\
\text { Good }=\end{array}$ & $\begin{array}{l}\text { Average=13 } \\
\text { Good }=\end{array}$ \\
\hline
\end{tabular}

Otoscopic examination and tympanometry results were within normal limits for all participants bilaterally, indicating no outer or middle ear pathology. Furthermore, all participants presented with normal hearing function based on basic hearing testing results with average pure tone air conduction thresholds of $8.92 \mathrm{~dB} \mathrm{HL}$ (see Table 2).

Table 2. Means of pure tone and speech reception thresholds ( $N=80$ ears)

\begin{tabular}{|l|l|}
\hline Stimulus & Mean \\
\hline PTA & 8.92 \\
\hline$C I D-S R T$ & 10.86 \\
\hline$T-S R T$ & 9.62 \\
\hline$D-S R T$ & 10.94 \\
\hline
\end{tabular}

\section{Speech Reception Thresbold Testing:}

Firstly, for all 3 lists, as indicated in Table 3, the correlation coefficient $(r)$ occurred between zero and one indicating that the two variables (SRT and PTA) tend to increase or decrease together, which is consistent with what is expected of SRT-PTA correlation in normal and diseased ears (Katz, 2002). Furthermore, regression analyses indicated that all 3 lists was acceptable speech stimuli for the population under investigation with the standard error of estimate being significantly smaller than the $5 \mathrm{~dB}$-step used to collect the data (1.62 for Tswana, 3.56 for CID W-1, and 3.80 for digit pairs).

A comparison of the results obtained from each of the three wordlists were statistically significant $(p<.05)$ in spite of the acknowledged small sample size. This means there was a statistically significant difference in the SRT-PTA correlations obtained using the three different wordlists. Thus the null hypothesis which stated that the participants' SRT-PTA correlation would be the same for all three lists utilized is rejected.

The results confirmed the alternative hypothesis in that participants presented with different mean SRT-PTA cor- relations between the three lists. The average SRT-PTA correlations for all participants for both left and right ears combined (see Table 2 ) reveal interesting and relatively reassuring findings when it comes to testing SRT in a multilingual country like South Africa, where dearth of resources in languages other than English is a reality.

Although, the differences between the lists were statistically significant, the results indicate that there generally seemed to be a fairly good correlation among all three test stimuli when compared to PTA. The Spearman's correlation coefficients (see Table 3), revealed that the highest correlation was that of the Tswana stimuli $(r=0.62)$, followed very closely by the CID W-1 $(r=0.61)$, and finally digit pairs ( $r$ $=0.60$ ). The highest correlation was with T-SRT wordlist, although this wordlist had not been formally standardized, which emphasizes the need for development of stimuli in languages other than English. Future research is needed regarding appropriate guidelines and criteria for developing speech stimuli material in Tswana.

Table 3. Spearman Correlation coefficients and standard error of estimates ( $N=80$ ears)

\begin{tabular}{|l|l|l|}
\hline \multicolumn{3}{|l|}{ Prob $>/ \mathrm{r} /$ Under $\mathrm{H0}$ : Rh0 $=0$} \\
\hline Stimulus List & $\begin{array}{c}\text { Correlation } \\
\text { value }\end{array}$ & $\begin{array}{l}\text { Standard error } \\
\text { of estimate }\end{array}$ \\
\hline CID-SRT & 0.61 & 3.56 \\
\hline T-SRT & 0.62 & 1.62 \\
\hline D-SRT & 0.60 & 3.80 \\
\hline
\end{tabular}

In the interim, where standardized wordlists in Tswana do not yet exist, results from the current study show that digit-pairs appear to offer an acceptable interim alternative for measuring the hearing thresholds for speech. Although there was a statistically significant difference $(p=0.01)$, this difference was deemed not large enough to warrant apprehension about utilizing an English wordlist or digits for second language English speakers who are educated and proficient in English. This belief is based on the growing recognition that researchers should not only focus on the statistical significance of the differences, but should also focus on the relevance or practical importance of these outcomes (Middel, 2002).

It is not surprising that the highest correlation was in Tswana as this is the participants' first language. This is consistent and correlates well with previous reports that state that the ideal speech material for speech audiometry is that which has a high level of familiarity, and has a representative sample of speech sounds in the patients' language (Hudgins et al., 1947 cited in Ramkissoon, 2002). In contexts where limited clinical resources result in dubious SRT testing, digit pairs may be considered. In this study digit pairs provided good correlation scores and therefore are possibly a useful speech stimuli to use in clinical settings in which a multicultural and multilingual clientele requires audiological services.

One needs to acknowledge the characteristics of the sample studied. All participants in the sample were proficient in English, had good literacy levels, were university students, 
and rated themselves as having average to good proficiency in English as their second language. They were all enrolled at a university which uses English as a medium of instruction, and were using English as a mode of communication on a daily basis. This sample is therefore not a fair representation of the general second language English speaking population in the country. The researchers, however, are of the belief that this is the ideal population to use in assessing sensitivity and accuracy of wordlists in multilingual populations. Bilingual proficiency is needed particularly when a comparison to performance on English wordlists is being studied. Thus linguistic skill will not be a confounding factor when the validity or reliability of test materials are researched. Generalizing the current findings to the general Tswana speaking population who do not fall within the described profile of the current sample would therefore be a significant error. Nevertheless, the fact that digit pairs were found to be acceptable stimuli in Ramkissoon et al's study (2002) where participants were not proficient in English (they had less than 1 year exposure to English and spoke English for less than 1 hour a day) motivates for the possible efficacy of their use in the South African population who are not proficient in English.

The aforementioned results support those of Ramkissoon et al (2002) as far as digit pairs are concerned. These authors found that digit pairs adequately measured the hearing threshold for speech in their sample of second language English speakers and that digit pairs were more sensitive than the CID W-1 wordlist. These results are consistent with those of the current study; however, in the current study the most sensitive measure was the Tswana word list. This emphasizes the fact that more efforts should be made to develop and standardize test material in languages other than English as a priority in all societies that are culturally and linguistically diverse. The use of alternative measures such as digit pairs should only be encouraged in the interim while the more sensitive measures are being developed. Ramkissoon et al (2002) did not assess SRT in their participants' first language, so one cannot comment on whether a similar finding as in the current study would have been observed in their study. Furthermore, in Ramkissoon et al.'s (2002) study, participants were not proficient in English as those in the current study.

The importance of sensitivity and accuracy of SRT measures in a multilingual society cannot be over-emphasized, particularly where a significantly large majority of audiologists do not speak or understand languages spoken by the larger section of the country's population. Basic audiometric test results such as pure tone threshold testing could also be compromised due to the client being unable to understand test instructions provided to them in an unfamiliar language. These results cannot be cross-checked on the basis of unreliable SRT results, calling into question the validity of the core components of the conventional audiological test battery,

\section{Summary of results}

Current findings confirm the efficacy of using digit pairs for SRT testing in the interim in populations who do not speak English as their first language, although the highest SRT-PTA correlation was obtained when the participant's native language was used. The results were statistically significant $(\mathrm{p}<.05)$ albeit the small sample size, and can be summarized as follows:

- $\quad$ SRT testing in Tswana-speaking, second-language English speakers can be performed utilizing digit pairs if resources do not exist in the patient's first language. This can only be as an interim measure though, since highest correlations were found with the participant's first language ( $T$ SRT-PTA).

- The participants' first language wordlist (Tswana) yielded the best SRT-PTA correlation scores, which highlights the need for developing and standardizing material in other languages in the country. It should be noted that these results were based on the speaker being proficient in Tswana.

\section{Conclusions and Implications}

Findings from this study are pertinent to the manner in which SRT testing is performed in multilingual populations. Although these results have the potential to contribute toward enhancing audiological assessment and management of hearing impairment in multilingual and multicultural populations, these results need to be considered in relation to issues identified in the project's research design and analysis. Critical scrutiny of the study revealed the following limitations:

- The limited availability of participants for this study resulted in a small sample size. As a result, the data obtained cannot be easily generalized to an entire Tswana speaking population. Furthermore, as mentioned earlier, the participants were proficient in English, utilized English on a daily basis, and were university students, which is not a representative sample of the second language English speaking population in South Africa.

- The T-SRT wordlist used is not a formally standardized wordlist and therefore this should be taken into consideration when interpreting the current findings.

The current study should be conducted on a larger scale with a larger sample size to ensure that results are generalizable. The Tswana wordlist that was utilized in this study should undergo a process of standardization and recording to ensure that it is used with the population that does not speak English nor is exposed to English on a daily basis.' This process should ensure that the criterion of familiarity of test items (Hudgins et al., 1947) is met. The impact of education and proficiency in the first language should also be taken into account. Recorded material will ensure that audiologists who do not speak Tswana can still use the stimuli and obtain reliable results that are not further negatively influenced by poor pronunciation and accent effects.

\section{References}

Battle, D. (1998). Communication disorders in multicultural populations. Stone ham: Andover Medical.

Berger, K.W. (1977). Speech audiometry materials. Ohio: Herald Publishing.

Bess, F.H. \& Humes, L.E. (2003). Audiology: The fundamentals ( $3^{\text {rd }}$ $E d)$. Philadelphia: Williams \& Wilkins."

Carhart, R. (1951). Basic principles of speech audiometry. Acta Otolaryngologic, 40, 62-71. 
Chapey, R. (1994). Language intervention strategies in adult aphasia. Baltimore: Williams \& Wilkins.

Cole, L. (1989). Eplurius pluribus: Multicultural imperatives for the 1990s and beyond. ASHA, 31, 9,65-70.

Devore, J.L. (1999). Probability and statistics for engineering and the sciences. California: Brooks/Cole Publishing Company.

Donaldson, B.C. (1991). The infuence of English on Afrikaans: A case study of linguistic change in a language contact situation. Pretoria: J.L. Van Schaik Ltd.

Feldman, H. (1970). A bistory of audiology. Translations Beltone Institute of Hearing Research, No. 22.

Frank, T. \& Craig, C.H. (1984). Comparison of the Auditec and Rintelmann recordings of NU-6.J Speech Hear Dis, 49, 267271.

Health Professions Council of South Africa (2003). Standards of practice in audiology. Professional Board for Speech, Language and Hearing Professions. August 28, 2008 from http://www. saslha.co.za/images/SLHStandardsof practiceinaudiology.doc.

Health Professions Council of South Africa (2008). Statistics of professionals registered with the board. Pretoria: HPCSA Statistics Department.

Heller, M.F. \& Bergman, M. (1953). Tinnitus aurium in normally hearing persons. Ann Otol Rbinol Laryngol, 62, 73-83.

Hodgson, W. (1980). Basic audiologic evaluation. Baltimore: Williams \& Wilkins.

Hood,J.D. \& Poole, J.P. (1980). Influence of the speaker and other factors affecting speech intelligibility. Audiology, 19, 434-455.

Howell, D. C. (1999). Fundamental statistics for the behavioral sciences. ( $4^{\text {th }}$ ed.). Boston: Brooks/Cole Publishing.

Hudgins, C.V., Hawkins, J.E., Karlin, J.E., \& Stevens, S.S. (1947). The development of recorded auditory tests for measuring hearing loss for speech. Laryngoscope, 57, 1, 57-89.

Jacobson, M.C. \& Trail, A. (1986). Assessment of speech intelligibility in South-eastern Bantu languages: Critical considerations. The South African Journal of Communication Disorders, 33.

Jerger, J.F. \& Hayes, D. (1976). The cross-check principle in pediatric audiometry. Arch Otolaryngol, 102, 614-620.

Jerger, J. \& Jerger, S. (1981). Auditory disorders: A manual for clinical evaluation (1t Ed) Little Brown \& Co: Boston.

Katz, J. (1994). Handbook of clinical audiology. Baltimore: Williams \&Wilkins.

Katz, J. (2002). Handbook of clinical audiology. Baltimore: Williams \& Wilkins.

Knight, J. (1997). Speech tests in other languages than English. In M. Martin (Ed), Speech audiometry, 315-324.

Kumar, R. (1999). Research methodology: A step by step guide for beginners. London: SAGE Publications.

Le Roux, J.C. (1991). Tswana. In C. Reynierse (Ed), South African multi-language dictionary $\&$ Pbrase book, South Africa: Readers Digest.

Lewis, R.E. \& Penn, C. (1989). Language Therapy: A program to teach English. Johannesburg: Witwatersrand University Press.

Lyregaard, P. (1976). On the relationship between recognition and familiarity of words. Tendington: NPL Acoustic Report AC78.

Martin, F.N. \& Clark, J.G. (2003). Introduction to audiology (8 ${ }^{\text {th }}$ Ed.). Boston: Allyn \& Bacon.

McLaughlin, B. (1984). Second language acquisition in childhood: Preschool Cbildren (2 ${ }^{\text {nd }} E d$ ). Hillsdale, NJ: Erlbaum.

Meyer, T.A. \& Bilger, R.C. (1997). Effect of set size and method on speech reception thresholds in noise. Ear and Hearing, 18,
202-209.

Middel, B. (2002). Statistical significant change versus relevant or important change in (quasi) experimental design: Some conceptual and methodological problems in estimating magnitude of intervention-related change in health services research. Int $J$ Intergr Care, 2, 1-22.

Miller, G.A., Heise, G.A., \& Lichten, W. (1951). The intelligibility of speech as a function of the context of the test materials. Journal of Experimental Psychology, 41, 329-340.

Pillay, B. (1996). A socio-economic atlas of South Africa. Pretoria: HSRC Publishers.

Punch, J.L. \& Howard, M.T. (1985). Spondee recognition threshold as a function of set size. Journal of Speech and Hearing Disorders, 50,120-125.

Ramkissoon, I., Proctor, A., Lansing, C., \& Bilger, R.C. (2002). Digit speech recognition threshold (SRT) for non-native speakers of English. American Journal of Audiology, 11, 23-28.

Ramkissoon, I. \& Khan, F. (2003). Serving multilingual clients with hearing loss: How linguistic diversity affects audiologic management. The ASHA Leader online Retrieved July 14, 2008 from $\mathrm{http}: / / \mathrm{www}$.asha.org/about/publications/leader-online/ archives $/ 2003 q 1 / 030218 \mathrm{a} . \mathrm{htm}$.

Republic of South Africa (1996). The constitution of the Republic of South Africa. Act No. 108 of 1996.

Roeser, R.J., Valente, M., \& Hosford-Dunn, H. (2000). Audiology diagnosis. New York: Harper \& Row.

Rosenthal, R. \& Rosnow, R.L. (1991). Essentials of bebavioural research: Methods and data analysis. New York: McGraw-Hill.

South African Medical Research Council. (2003). General principles including research in children, vulnerable groups, international collaboration and epidemiology. Retrieved October 16, 2005 from http://www.sahealthinfo.org/ethics/ethicspolicy.htm.

Schiavetti, N. \& Metz, D.E. (2002). Evaluating research in communicative disorders (4 $4^{\text {th }}$ Ed.). Boston: Allyn \& Bacon. 


\begin{tabular}{|c|c|c|c|c|c|c|c|c|c|}
\hline \multicolumn{4}{|c|}{$\begin{array}{c}\text { Appendix A } \\
\text { CID W-1 English wordlist }\end{array}$} & \multicolumn{6}{|c|}{$\begin{array}{c}\text { Appendix B } \\
\text { Setswana/Tswana SRT wordlist }\end{array}$} \\
\hline $\begin{array}{l}\text { List A } \\
\text { Greyhound } \\
\text { Schoolboy } \\
\text { Inkwell } \\
\text { Whitewash } \\
\text { Pancake } \\
\text { Mousetrap } \\
\text { Eardrum } \\
\text { Headlight } \\
\text { Birthday } \\
\text { Duckpond } \\
\text { Sidewalk } \\
\text { Hotdog } \\
\text { Padlock } \\
\text { Mushroom } \\
\text { Hardware } \\
\text { Workshop } \\
\text { Horseshoe } \\
\text { Armchair } \\
\text { Baseball } \\
\text { Stairway } \\
\text { Cowboy } \\
\text { Iceberg } \\
\text { Northwest } \\
\text { Railroad } \\
\text { Playground } \\
\text { Airplane } \\
\text { Woodwork } \\
\text { Oatmeal } \\
\text { Toothbrush } \\
\text { Farewell } \\
\text { Grandson } \\
\text { Drawbridge } \\
\text { Doormat } \\
\text { Hothouse } \\
\text { Daybreak } \\
\text { Sunset }\end{array}$ & $\begin{array}{l}\text { List B } \\
\text { Playground } \\
\text { Grandson } \\
\text { Daybreak } \\
\text { Doormat } \\
\text { Woodwork } \\
\text { Armchair } \\
\text { Stairway } \\
\text { Cowboy } \\
\text { Oatmeal } \\
\text { Railroad } \\
\text { Baseball } \\
\text { Padlock } \\
\text { Hardware } \\
\text { Whitewash } \\
\text { Hotdog } \\
\text { Sunset } \\
\text { Headlight } \\
\text { Drawbridge } \\
\text { Toothbrush } \\
\text { Mushroom } \\
\text { Farewell } \\
\text { Horseshoe } \\
\text { Pancake } \\
\text { Inkwell } \\
\text { Mousetrap } \\
\text { Airplane } \\
\text { Sidewalk } \\
\text { Eardrum } \\
\text { Greyhound } \\
\text { Birthday } \\
\text { Hothouse } \\
\text { Iceberg } \\
\text { Schoolboy } \\
\text { Duckpond } \\
\text { Workshop } \\
\text { Northwest }\end{array}$ & $\begin{array}{l}\text { List C } \\
\text { Birthday } \\
\text { Hothouse } \\
\text { Toothbrush } \\
\text { Horseshoe } \\
\text { Airplane } \\
\text { Northwest } \\
\text { Whitewash } \\
\text { Hotdog } \\
\text { Hardware } \\
\text { Woodwork } \\
\text { Stairway } \\
\text { Daybreak } \\
\text { Sidewalk } \\
\text { Railroad } \\
\text { Oatmeal } \\
\text { Headlight } \\
\text { Pancake } \\
\text { Doormat } \\
\text { Farewell } \\
\text { Mousetrap } \\
\text { Armchair } \\
\text { Drawbridge } \\
\text { Mushroom } \\
\text { Baseball } \\
\text { Grandson } \\
\text { Padlock } \\
\text { Greyhound } \\
\text { Sunset } \\
\text { Cowboy } \\
\text { Duckpond } \\
\text { Playground } \\
\text { Inkwell } \\
\text { Eardrum } \\
\text { Workshop } \\
\text { Schoolboy } \\
\text { lceberg }\end{array}$ & $\begin{array}{l}\text { List D } \\
\text { Hothouse } \\
\text { Padlock } \\
\text { Eardrum } \\
\text { Sidewalk } \\
\text { Cowboy } \\
\text { Mushroom } \\
\text { Farewell } \\
\text { Horseshoe } \\
\text { Workshop } \\
\text { Duckpond } \\
\text { Baseball } \\
\text { Railroad } \\
\text { Hardware } \\
\text { Toothbrush } \\
\text { Airplane } \\
\text { Iceberg } \\
\text { Armchair } \\
\text { Grandson } \\
\text { Playground } \\
\text { Oatmeal } \\
\text { Northwest } \\
\text { Woodwork } \\
\text { Stairway } \\
\text { Hotdog } \\
\text { Headlight } \\
\text { Pancake } \\
\text { Birthday } \\
\text { Greyhound } \\
\text { Mousetrap } \\
\text { Schoolboy } \\
\text { Whitewash } \\
\text { Inkwell } \\
\text { Doormat } \\
\text { Daybreak } \\
\text { Drawbridge } \\
\text { Sunset }\end{array}$ & $\begin{array}{l}\text { List A } \\
\text { Seretse } \\
\text { Ngwanyana } \\
\text { Mogogi } \\
\text { Letsogo } \\
\text { Sediba } \\
\text { Logong } \\
\text { Namane } \\
\text { Lokwalo } \\
\text { Letsatsi } \\
\text { Lengoele } \\
\text { Mosadi } \\
\text { Leswana } \\
\text { Setthako } \\
\text { Moruti } \\
\text { Leswana }\end{array}$ & $\begin{array}{l}\text { List B } \\
\text { Lefifi } \\
\text { Letsoo } \\
\text { Nama } \\
\text { Letsat } \\
\text { Tumel } \\
\text { Ngwar } \\
\text { Moruti } \\
\text { Letsog } \\
\text { Setshe } \\
\text { Phetos } \\
\text { Setlha } \\
\text { Legon } \\
\text { Moriti } \\
\text { Leswa } \\
\text { Boroth }\end{array}$ & 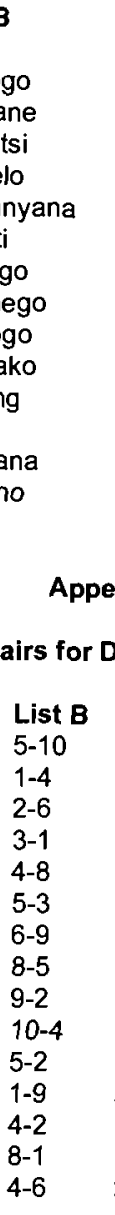 & 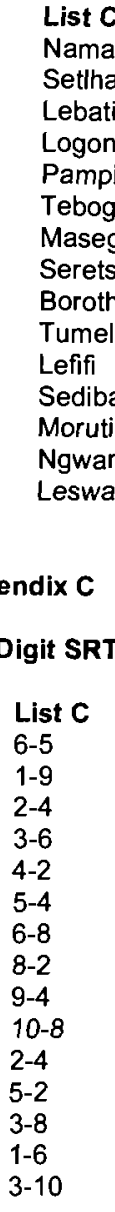 & $\begin{array}{l}\text { testing } \\
\text { List } \\
5-2 \\
6-9 \\
3-1 \\
10-4 \\
1-6 \\
2-8 \\
3-9 \\
4-3 \\
5-1 \\
6-5 \\
5-3 \\
8-5 \\
1-4 \\
2-6 \\
9-4\end{array}$ & $\begin{array}{l}\text { List D } \\
\text { Borotho } \\
\text { Sethako } \\
\text { Monwana } \\
\text { Mosadi } \\
\text { Mogogi } \\
\text { Sediba } \\
\text { Lenyalo } \\
\text { Lengoele } \\
\text { Letsatsi } \\
\text { Ngwanyana } \\
\text { Lebati } \\
\text { Namane } \\
\text { Masego } \\
\text { Sethare } \\
\text { Moruti }\end{array}$ \\
\hline
\end{tabular}

